\title{
Complementor-side Ecology and its Implications on Platform Strategy
}

\author{
Sungho Lee \\ Yonsei University \\ 1shpro77@gmail.com
}

\author{
Sung Joo Bae \\ Yonsei University \\ sjbae@yonsei.ac.kr
}

\author{
Mooweon Rhee \\ Yonsei University \\ $\underline{\text { mooweon@yonsei.ac.kr }}$
}

\author{
Minah Park \\ Yonsei University \\ $\underline{\text { minahp@yonsei.ac.kr }}$
}

\begin{abstract}
Understanding the complementor behavior and its implication is the key to understanding platform dynamics. By using theoretical guides of organizational ecology, this study analyzed complementor's various niche strategies and their implications. Using the data from game industry, our study shows that the initial entry strategy to increase the survival rate is to concentrate on a specific game genre. However, as the platform grows, the relationship between complementor platform niche width and the survival rate shows inverted-U shape. From the perspective of the platform owner, it would be very difficult to provide various kinds of services especially at the early stage of developing the platform if all the complementors become genrespecific. If many complementors choose to provide services to multiple platforms, it would be very difficult for the platform owner to provide services different from other platforms. We provide interpretations on various strategic implications of complementor dynamics to the platform strategy.
\end{abstract}

\section{Introduction}

Platform is emerging as the core part of value chains in technology industries, which generates the value through connecting complementor's effort with the needs of the users $[1,2]$. Due to its ability to facilitate active interaction among entities, platform is widely used in various fields [3] and becoming a dominant business model, especially in the software industry [4]. Platform consists of end users, complementors, and platform owners [1, 5-8]. Different participants join a platform and they each play unique role, which may be opened or closed depending on the structure of the platform [5, 8-10]. Among these actors, this research paper specifically focuses on the complementors and how the platform dynamics impact their strategic behavior.
While traditional business model involves upstream suppliers and downstream buyers, the most distinct feature of the platform is the emergence of network effect. Network effect implies that the introduction of new users in the network causes growth of an existing market $[11,12]$. The network effect in the platform can be subdivided into direct and indirect network effect. Direct network effect implies as the number of the platform users increases, the value of the platform increases as well, resulting in the attraction of more users [11]. On the other hand, indirect network effect exerts influence on the complementors. Increased number of users in the platform promotes the growth of the platform. This motivates complementors to make platform-specific investment by developing service and deciding to join the platform [13].

Although existing studies have provided deep insights into various strategies of platform owners to facilitate network effect and platform growth, limited attention has been paid to understand the strategy and motivation of complementors. Some scholars observed the effect of complementors or users joining multiple platforms which is known as multi-homing [14-18]. However, studies were performed with viewpoint of owners and do not include the effect of platform growth on complementors and their strategic behaviors. Without their willingness to make investment to the application development of a platform, the platform is unable to attract users [9]. Hence, it is important to understand the strategic behavior of the complementors who act as providers of services in a platform. Throughout the paper, we attempt to offer the interpretation behind strategic actions of complementors with the theories from organizational ecology (OE). Building on organizational ecology theory, we investigate the strategies adopted by the complementors during the entry to the platform and growth of the platform. Furthermore, we analyze the effects of different strategies of the complementors on the platform in game industry. 
To sum up, this research investigates the strategic behavior of complementors by focusing on two major research questions: (1) How does platform's creation and growth affect the complementors? (2) What strategies do the complementors implement for their survival and growth, and how do they affect platform in turn? By providing answers to these research questions, this study contributes to literature of platform in several ways. First, we observe the effect of platform growth on complementors and attempt to extend previous research by providing explanation for dynamics of complementors using the density dependence theory of organizational ecology. Second, we consider strategies of complementors when they are participating in multi-platforms. Third, we examine various strategies executed by complementors and their effects on the platforms in two different situations: when the complementors are entering to the platform and when the platform is expanding.

\section{Literature review and hypothesis}

\subsection{Organizational ecology in platform}

Theory of OE provides a useful tool to apprehend organizational diversity and dynamics by revealing effects of exogenous organizational factors and endogenous organizational factors on the founding, growth, and failure of organization [19]. Exogenous factors include social resources, political power, and technological innovation that are not under the control of the organization [20]. On the contrary, the endogenous factors that cause the dynamics of population and the interactions of organization are the population density, age, size of organization, niche width, and location [21-24]. As follows, research in $\mathrm{OE}$ considers both exogenous and endogenous factors as the causes of the various changes to the organization. Furthermore, as a prevalent framework for understanding the organization as an outcome of competition and selection processes, OE emphasizes the acquisition of niche. A niche refers to the segment in the market defined by the resources required for organizational survival $[25,26]$. Depending on the size of niche, organization can be categorized into specialists and generalists [25]. As the resource becomes scarce in the environment, competition progressively intensifies, interfering the founding and evolution of organizations [25, 27, 28].

In this paper, we attempt to view platform with the theoretical lens of OE. In the platform, platform owners and complementors are considered as having separate populations. Interaction between them results in the growth of platforms by promoting network effect. Expansion of the platform implies more opportunity is provided for the complementors to make a sale, but it also means that new complementors are introduced to the platform, increasing the competition level. According to $\mathrm{OE}$, organizations compete within a physically limited area also known as a region [29]. Likewise, complementor is able to provide their services only through the platform, therefore, in other words, complementors operate within the boundary of the platform. However, this boundary is not a closed boundary. Rather, it can be considered as an open boundary because it allows complementors to join or leave to different platform, which is one of the strategies complementors employ for their growth and survival. Thus, in a platform, complementors are able to freely select and migrate to different platforms or even join multiple platform at a time, providing services to users.

\subsection{Network effect \& density dependency in platform}

In the platform, although network effect acts favorably for platform owners by attracting more users and complementors, from the perspective of the complementor, increased number of complementors by the network effect can influence them negatively through the density effect. As the platform expand, not only new users join the platform but complementors participate into the platform. As the number of complementors increases, it creates competitive situation for the complementors, threatening the survival of the complementors. Specifically, density dependence theory argues that the change in population density leads to the process of organization's legitimation and competition [30].

The concept of localized competition in OE distinguishes competition into two types: organizations within the entire population and competition among organizations that are locally close [29]. First, when the concept of organizational competition within the entire population is applied to the complementors, complementors do not necessarily have to go through the process of legitimation. In the early days of the market, the social legitimacy of the market is fairly weak, thus it is not viewed as an attractive for the complementor to invest in due to the difficulty in the resources acquisition. However, platform owners promote the participation of new users to the market, which 
enhances the network effect and increases the value of the market [11]. Increased value leads to the expansion of the market where complementor can provide services, thereby enhancing the legitimacy. Thus, once the platform owner population develops legitimacy, it facilitates the participation of new complementors into the platform. By participating in to the market where legitimacy is already developed, complementors can omit the process of legitimacy but experiences the process of competition right away as the density increases. If the process of legitimation was necessary for the complementors, the mortality rate should decrease as density increases until the process of competition begins. Thus, a positive relationship between population density of complementors and their organizational mortality should be observed right away.

H1a: There is a positive relationship between population density of complementors and their organizational mortality.

It is also important to examine the competition of complementors within a platform, which can be perceived as a localized competition among organizations that are locally close [29]. Although there is competition among organizations within the entire population, severe competition is also observed within the platform. The boundary of the platform is an open boundary which allows complementors to move freely from the one platform to another according to their strategic decisions. This causes constant changes in the density of complementors in a platform. Thus, due to the unique feature of the platforms, not only the population density is important but also the density of the complementors in the platform needs to be taken into account. Similarly, complementors do not have to experience the process of legitimation because the formation of the platform implies that legitimacy already exists. The legitimacy of platform is directly transferred to complementors, exposing to the competition effect from early on. As density of complementors in platform continues to increase, competition among complementors intensifies, which results in higher mortality rate. Therefore, we made the following assumptions regarding the effect of complementor density in platform.

H1b: There is a positive relationship between density and mortality of complementors within platform.

\subsection{Complementor's niche strategy in platform}

Niche is a resource for organization's survival and growth, and it can also be perceived as a range of its activities [21], thus complementors must secure niche. Depending on the degree of width, organization can be classified in to a generalist (wide niche) or a specialist (narrow niche). Niche is not only a physical resource required for an organization to survive, but it is also associated with an identity, an perception that external audience have regards the organization $[31,32]$. Furthermore, a platform NW strategy, is also associated with multi-homing in platform studies. Complementor adopting multi-homing strategy would reduce differentiation between platforms [17, 33]. While most of multi-homing studies discuss the effects of multi-homing on the platform [15, 16, 18], few studies are related to the the advantages complemetors gained by implementing the multihoming strategy [34-36].

If the behavior of the organization is aligned with its identity, their value will be recognized by customers, but customers will devalue the organization if the behavior and identity are not coordinated [31, 37]. For instance, an organization with simple identity has the advantage of allowing customers to easily recognize and classify the organization. However, the simple identity constrains the organization to pursue various strategic actions [38]. On the other hand, organizations with complicated identities are not subject to specific categories, thus less constrained by organizational behavior. However, this makes it difficult for customers to recognize and specify their identities [39]. As such, niche can be perceived as the both a necessary resource as well as the identity

To quickly obtain network effect and secure user base, in terms of niche, there are two strategic choices that complementors need to decide: platform niche width (platform range) and genre niche width (service range) First, platform niche width (NW) refers to the platform scope of the complementors. While organizations compete in a regionally limited and fixed area, complementors can decide to join a single or multiple platforms freely according their strategy. Depending on whether complementors execute strategy of generalist or specialist, there are different advantages and disadvantages in terms of customer base and platform technology optimization. If complementors decide to adopt generalist strategy and provides services across multiple platforms with wide platform $\mathrm{NW}$, the organization is able to quickly increase the network effect through its broad customer base in multiple platforms [40]. Generalist strategy have advantage of distributing the risks associated with high development costs [34]. However, disadvantage of a generalist strategy 
includes high development cost due to customization of the services according to the technical features of each platform, which may result in the low service quality. On the other hand, if complementors adopt the strategy of specialist by narrowing platform NW and providing service to a single platform, it is highly likely that a complementors are able to provide optimized services to the platform. But, because specialist strategy targets specific platform, complementors retain narrow customer base and is greatly influenced by that particular platform.

Second decision that the complementor has to make is genre NW, customer base that complementors aim to satisfy through their services. Genre NW strongly affects the 'identity' that is formed amongst the audience. Audience views these organizational properties and builds expectation toward the organization. These expectations often constrain the activities of organization because observation made by the audience whether the organization violate or satisfy the codes impacts the audience's social approval of an organization. If complementors adopt the wide genre NW of generalist, it can secure wide customer base by satisfying diverse preferences of users. In addition, complementors can flexibly respond to environmental changes, such as changes in the user taste. However, complicated identity of complementors makes it difficult for users to recognize the organization quickly $[38,39,41]$. On the other hand, the complementors, who choose the genre NW of specialist, has the advantage of organizational identity being promptly recognized by the user and quickly acquiring the customer base in a specific service area. However, when complementors with the identity as the specialist attempt to broaden the NW, users may devalue their action and feel resistance. Likewise, platform NW and genre NW strategies of generalist and specialist exhibit different advantages and disadvantages in terms of customer segment and identity.

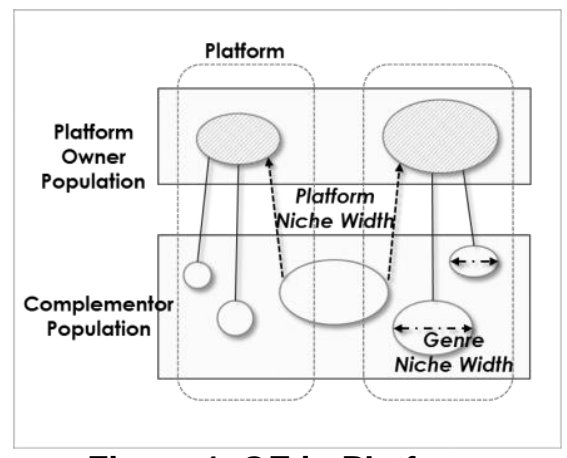

Figure 1. OE in Platform

\subsection{Entry strategy of complementor to a platform}

When participating in the platform, complementors select platform NW and genre NW strategy [42]. In the case of platform NW, it is beneficial for complementors to adopt generalist's platform NW strategy. It allows them to serve multiple platforms and lower their mortality rate. Because the entry cost to platform is relatively low, participating to multiple platform is not difficult, allowing the benefit of acquiring greater number of users [42]. Although there are risks of not being able to develop high quality services due to the different platform's technological environments, the wide platform NW reduces the risk of service failures by broadening the organizational activity to multiple platforms. By preventing the risk of the service failure, it lowers the dependency of complementors on a specific platform, thereby providing autonomy to the organizational activity. In addition, it is possible to enjoy economies of scale and scope by creating large-scale services based on a broad customer base. Therefore, we made the following assumption for platform NW of generalist and organizational mortality rate when complementors enter to the platform.

$\mathrm{H} 2$ : There is a negative relationship between entry platform NW and mortality of complementors.

In reference to the complementors' genre NW during the entry to the platform, complementors with narrow genre NW will have lower possibility of failure. Executing genre NW of specialist allows complementors to provide high quality and specialized services to users by focusing on a specific service genre. The strategy of service diversification eases the process of expanding service in the future, which implies to the high level of adaptability to external environmental changes [39]. However, in the early stage of the organization, factors such as immature organizational capacity and limited resources constrain the organizational activity [19]. Therefore, it is better for complementors to provide a high-quality and specialized service. Additionally, a strategy to focus organizational capabilities on a specific genre allows users to quickly recognize an organization as a specialist (Hsu \& Hannan, 2005), which results in the securing users quickly with specialized service and promoting the network effect. Based on distinct identity and differentiated competitiveness during the early stage, the complementor is able to quickly attract users and lower the mortality rate of organization. Therefore, 
we made the following assumption for genre NW of specialist strategy and organizational mortality rate when complementors enter the platform.

H3: There is a positive relationship between entry genre NW and mortality of complementors.

\subsection{Complementors' niche strategy in platform growth}

As the platform grows, complementors may alter strategy of platform NW and genre NW to survive in a competitive market. However, their strategies may differ from those adopted when entering to the platform. As competition becomes more intense within the platform, complementors adopt platform NW strategy of specialist or generalist and both of the strategy positively affect the organizational survival. If complementors implement platform NW of specialist, it increases the survival rate by expanding users with specialized services that target the specific customer base [43]. It also enhances the expertise, thus increase the chance of organization's survival. Moreover, it provides a strong relationship with the platform owner that offers opportunity for complementors to secure additional resources and special attention. On the other hand, it is also beneficial for complementors to execute the generalist's platform NW strategy. Participating into multiple platforms results in the market diversification [44]. Furthermore, it leads to the expansion of customer base, risk distribution, economies of scale, and lowers the organization's mortality rate. Therefore, implementing either one of the strategy will lower the mortality rate of the complementor. However, expanding services from a single platform to multiple platforms requires conversion of existing service because each platform is characterized by different technological features. This process requires additional investment for developing optimized services for each platform and maintenance cost. If complementors lack capability and resources, the process of adopting a generalist strategy would increase the mortality rate. But the process of continuously broadening platform NW facilitates accumulation of knowledge regarding technology and service maintenance and eventually enhances the organizational capability. Therefore, we made the following assumption for platform $\mathrm{NW}$ and organization mortality rate in the competitive environment.

H4: There is an inverted- $U$ relationship between a platform NW and mortality of a complementor.
Second, complementors can similarly change genre NW as the platform grows by implementing either one of specialist or generalist's strategy. If a complementors adopt strategy of specialist with narrow genre NW, it increases organizational capabilities for that genre and lower the rate of organizational mortality. But, as competition intensifies, complementors attempt to increase organizational viability through broadening genre NW. A strategy that meets various needs of users through a wide range of genres can provide new value to existing users and attract new users who are not satisfied with current services. Especially, it can reduce the risk that is associated with the evaporation of demand within the specific genre. However, if complementors has imprinted their identity as specialist to users, users may feel reluctant to complementors, broadening genre NW and modifying the identity, [45]. Also, the expansion of genre NW from narrow to wide requires new organizational capabilities and additional resources to develop services in new genres. Nonetheless, in long term, the strategy of expanding genre NW widens scope of organizational activities, thus reduces the organization's mortality rate. Once complementors develop capability to create high quality games in different genres and establish identities as a generalist, this can be extremely beneficial. Therefore, we made the following assumption for genre NW and organization mortality rate in competitive environment.

H5: There is an inverted- $U$ relationship between a genre NW and mortality of a complementor.

\section{Research and method}

The game industry can be perceived as a typical platform industry composed of a game console company as a platform owner, game developer as a complementor, and game players as users. The data was collected from 1977 to 2014, which is a sufficient period to observe the founding and failure of complementors.

\subsection{Data}

We targeted video game developers from 1977 to 2014 in order to analyze the strategic behaviors of the complementors. We collected data regarding the game company history and game titles released by game developers. Then collected data was crossvalidated with video game open sites such as "Mobygames.com", "Vgchartz.com", and Wikipedia. 
The final data includes 1,737 game developers, excluding the companies that do not have company history information and released game information.

\subsection{Variable}

\subsubsection{Mortality event}

The reasons for game developer failure can vary, but mainly they can be classified into three categories: 1) disbanding of the firm; 2) exit to another industry; and 3) merger or acquisition by another firm. We categorized firms into two types: 1) disbanding of the firm if firm is recorded by bankruptcy or close and 2) exit to another industry in our data but there aren't cases of type 2. Also, we did not included third types because it was difficult to decide whether the merger was due to success or failure of the firm's game.

\subsubsection{Population variable}

Population Density: It is defined as the number of organizations in the game developer population in each year. Founding point of organization is measured as January of the year, and failure point of organization is measured as December of year.

Platform Density: It represents a number of complementors within a platform which complementor participate in. If a complementor is participating in multiple platforms, we sum densities of complementors in each platforms. Finally we calculate the platform density by adding weight which refers to a number of platform that complementor participate in.

$$
\text { Platform Density }_{j}=\sum_{i=1}^{N} \text { Desnity }_{i} \times S_{i} \times C_{i j}
$$

$\mathrm{D}$ : The number of complementors participated in platform $i$ each year.

$\mathrm{S}_{\mathrm{i}}$ : The portion of density of platform $i$ out of sum of density from all platform each year.

$C_{i j}$ : Whether the complementor $\mathrm{j}$ releases game title in platform $i$ each year or not.

\subsubsection{Organizational variable}

Age: The time from creation of the organization to the time of the death is measured.

Size: The size of the organization can be measured in various ways such as the sales of the organization or the number of employees. However, the organization size is relatively small in the game platforms, resembling the venture company. Thus, the number of game titles is employed to measure the size of organization.

Organization Niche Width: platform niche refers to the scope where the game developers aims to release the game, while genre niche represents the genre scope of game. In this paper, we categorize 34 game platforms, including game consoles and mobile game platforms developed by game platform manufactures. Game genres are categorized into eight genres: action, adventure, education, racing, role playing, simulation, and sports. Platform NW and genre NW in the game industry can be understood in terms of concentration of game developer on the platform and on the genre when launching the game. For example, if the games are released to multiple platforms, the platform $\mathrm{NW}$ is perceived as less concentrated. Also, if the complementor develops several genres of games, the genre NW is described as less focused. We use HHI (Herfindahl-Hirschman Index) to measure concentration on platform and genre [46]. The HHI is a measurement of the concentration in the industry and is suitable for measuring platform concentration and genre concentration. However, the lower the concentration of $\mathrm{HHI}$, that is, the more convergent to 0 , the larger the Niche. Therefore, for the sake of cognitive convenience, the HHI value was inversely transformed so that the HHI value increases as the Niche width increases.

$$
H H I=\sum_{i=1}^{N} s_{i}^{2}
$$

Genre Niche Width: 1/HHI (N: Number of Genre each year, $s_{i}$ : Portion of Genre $\mathrm{j}$ in Released Game each year )

Platform Niche Width: 1/HHI (N: Number of Platform by year, $S_{i}$ : Portion of Platform $\mathrm{j}$ in Released Game each year )

Platform Entry Strategy: We measured platform NW and Genre NW for three years after the game developers participate in the game platform and launched games for the first time. According to the ESA data in 2013, the average period of game development is 1.6 years. Hence, the period of three years is sufficient time to observe the initial platform entry strategy.

Niche Width Strategy: We measured the Platform NW and Genre NW for three years. The three-year period was decided considering the average game development period of 1.6 years. 


\subsubsection{Environment variable}

Market Size: Changes in the size of the game market affect the growth of the platform, thus we reflect the revenue of the game industry as a variable.

Recession: Economic downturn is considered as an external factor and it is treated as a dummy variable.

Industry Event: In order to reflect the characteristics of the game industry, the bankruptcy timing of game industry due to low quality game from 1983 to 1985 is included.

Technology Change: In the case of video consoles, due to the technological innovation, the game platform manufacture introduces new game console periodically. Research model reflects the timing of technology changes as dummy variables since they have a great impact on the platform industry.

Platform Dummy: Each platform has different business policy and technological characteristics. We included characteristics of 31 platform to model as dummy variable.

Genre Dummy: We categorized game title into 8 types (action, adventure, education, racing, roleplaying, simulation, sports, and strategy) which is based on "mobygames.com" and "Vgchartz.com". We reflected genre to model as dummy variable.

\subsubsection{Model specification and estimation}

We use a piecewise constant exponential model in history analysis that does not assume any specific pattern between age and mortality. A piecewise constant exponential model divides organizational age into several periods, and then calculates the relationship between organizational age and mortality rate within each period. In this case, the mortality rate in each period has the maximum value allowed by the data without any assumption, and has the same mortality rate within each period. The total duration of the organizational age is divided into section $0 \leq \tau_{1} \leq \tau_{2} \leq \cdots \leq \tau_{p}$ and is divided into $\mathrm{P}$ sections with the assumption of $\tau_{p+1}=\infty$. The interval setting is divided into seven intervals 02921 $51126573 \quad 9130 \quad 9860 \quad 10226$ through several measurements with reference to the life table.

Therefore, the mortality rate of the organization in the individual section is expressed as $\lambda_{i p}=\lambda_{p} \exp \left\{x_{i}^{\prime} \beta\right\}$. Here, $\lambda_{i p}$ is the mortality rate of the organization $i$ in the interval $\mathrm{p}$, and $\lambda_{p}$ is the baseline hazard of the interval p. $x_{i}^{\prime}$ is the covariate variable that affects the mortality rate of the organization. In this paper, market size, recession, industry event, and technology change are included as external variables and organization size is included as an intrinsic variable of the organization.

\section{Finding}

To test our hypotheses, we use the piecewise constant exponential model. In each model, market size, recession, industry event, technology change and effect of age are included. Model 1 includes only population density and platform density and in model 2, we add the entry NW. For model 3, current NW such as platform NW and genre NW are incorporated. Finally, model 4 provides the full model with all controls and independent variables.

Table 1. Complementor's survival analysis

\begin{tabular}{l|r|r|r|r}
\hline Label & Min & Max & Mean & $\begin{array}{c}\text { Std. } \\
\text { Dev. }\end{array}$ \\
\hline Firm's Size & 0 & 200 & 1.36 & 4.467 \\
Market Size & 400 & 76000 & 46504 & 18515 \\
Recession & 0 & 1 & 0.249 & 0.433 \\
Industry Event & 0 & 1 & 0.014 & 0.119 \\
Tech. Change & 0 & 1 & 0.329 & 0.47 \\
PopulationDensity & 4 & 2162 & 1652.0 & 599.76 \\
PlatformDensity & 0 & 21994 & 1148.2 & 1819.2 \\
Entry PlafformNW & 0 & 7.758 & 0.81 & 1.183 \\
Entry GenreNW & 0 & 4.571 & 0.659 & 1.003 \\
CurrentPlatformNW & 0 & 7.758 & 1.292 & 1.042 \\
CurrentPlatformMW & 0 & 4.898 & 1.115 & 0.781 \\
\hline
\end{tabular}

To investigate the effects of environmental factors in game platform industry, we statistically analyze the effect of market size, recession, industry event and technology change. The results show that market size lowered the mortality rate of complementors by expanding market space and niche space where complementors can actively provide their services. Atari Shock, representing the industry period variant, has significant effect on the complementor's mortality rate by providing of low-quality games to users and threating credibility of the game industry. In terms of technology change in the platform, game console manufactures periodically replace platform console due to the introduction of technological innovation to the game industry. This technological advance is perceived as an opportunity for complementors to provide new games based on platform's innovative technology, but it can also act as a threat for the organization if organization fails to adapt the technology.

In H1a, we propose that there is a positive relationship between population density of complementors and their organizational mortality. In 
Table 2, we note a positive coefficient for the population density of complementors and their organizational mortality (Model I: beta $=0.874, \mathrm{p}<.05$ ), in support of H1a. Additionally, we test the positive effect of platform density of complementors on mortality of a complementor within a platform, in $\mathrm{H} 1 \mathrm{~b}$. Because the results show that the coefficient is positive (Model I: beta $=0.289, \mathrm{p}<.001$ ), they support H1b.

Table 2. Complementor's survival analysis

\begin{tabular}{|c|c|c|c|c|}
\hline Variable & Model I & Model II & Model III & Model IV \\
\hline $\begin{array}{l}\text { Organization } \\
\text { Age1 } \\
\text { Age2 } \\
\text { Age3 } \\
\text { Age4 } \\
\text { Age5 } \\
\text { Age6 } \\
\text { Age7 } \\
\text { Size } \\
\end{array}$ & $\begin{array}{r}-17.689(2.448)^{\star * *} \\
-17.439(2.451)^{\star * *} \\
-17.314(2.457)^{* * *} \\
-17.402(2.466)^{* * *} \\
-17.43(2.521)^{\star * *} \\
-17.599(2.648)^{* * *} \\
-17.302(2.493)^{\star * *} \\
-0.022(0.026)\end{array}$ & $\begin{array}{r}-18.257(2.46)^{\star * *} \\
-18.018(2.463)^{\star * *} \\
-17.919(2.471)^{\star * *} \\
-18.028(2.48)^{\star * *} \\
-18.088(2.536)^{\star * *} \\
-18.246(2.661)^{\star * *} \\
-17.966(2.508)^{\star * *} \\
-0.02(0.026)\end{array}$ & 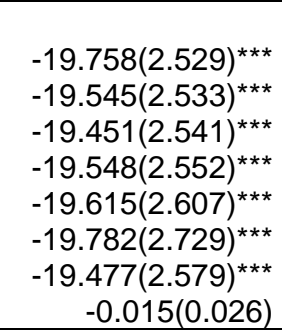 & $\begin{array}{r}-19.72(2.531)^{\star \star *} \\
-19.52(2.535)^{\star * *} \\
-19.443(2.543)^{\star * *} \\
-19.553(2.554)^{\star \star *} \\
-19.64(2.609)^{\star * *} \\
-19.789(2.731)^{\star \star *} \\
-19.502(2.581)^{\star * *} \\
-0.017(0.026)\end{array}$ \\
\hline $\begin{array}{l}\text { Environment } \\
\text { Market Size } \\
\text { Recession } \\
\text { Industry Event } \\
\text { Technology Change }\end{array}$ & $\begin{array}{r}-0.00002(6 \mathrm{e}-06)^{\star \star \star} \\
0.354(0.156)^{\star} \\
2.177(0.828)^{\star *} \\
-0.294(0.162)+\end{array}$ & $\begin{array}{r}-0.00002(6 \mathrm{e}-06)^{\star \star \star} \\
0.356(0.156)^{\star} \\
2.233(0.831)^{\star *} \\
-0.294(0.162)+ \\
\end{array}$ & $\begin{array}{r}-0.00002(6 e-06)^{\star * *} \\
0.354(0.156)^{*} \\
2.344(0.837)^{\star *} \\
-0.305(0.162)+\end{array}$ & $\begin{array}{c}-0.00002(6 \mathrm{e}-06)^{\star \star *} \\
0.355(0.156)^{*} \\
2.325(0.84)^{\star *} \\
-0.301(0.162)+\end{array}$ \\
\hline $\begin{array}{l}\text { Population } \\
\text { Population Density(log) } \\
\text { Platform Density(log) } \\
\text { Platform1 Platform31 } \\
\text { Genere1 Genre8 }\end{array}$ & $\begin{array}{r}0.874(0.36)^{\star} \\
0.289(0.058)^{\star * *} \\
\text { omitted } \\
\text { omitted }\end{array}$ & $\begin{array}{r}0.904(0.361)^{*} \\
0.238(0.061)^{\star * *} \\
\text { omitted } \\
\text { omitted }\end{array}$ & $\begin{array}{r}1.142(0.365)^{\star *} \\
0.142(0.069)^{*} \\
\text { omitted } \\
\text { omitted }\end{array}$ & $\begin{array}{r}1.024(0.365)^{* *} \\
0.145(0.069)^{*} \\
\text { omitted } \\
\text { omitted }\end{array}$ \\
\hline $\begin{array}{l}\text { Entry Niche Width } \\
\text { Platform NW } \\
\text { Genre NW }\end{array}$ & & $\begin{array}{l}0.093(0.086) \\
0.38(0.11)^{\star \star \star}\end{array}$ & & $\begin{array}{l}-0.051(0.105) \\
0.309(0.121)^{*}\end{array}$ \\
\hline $\begin{array}{l}\text { Current Niche Width } \\
\text { Platform NW } \\
\text { Platform NW^2 } \\
\text { Genre NW } \\
\text { Genre NW^2 }\end{array}$ & & & $\begin{array}{r}1.013(0.306)^{\star * *} \\
-0.134(0.058)^{*} \\
0.691(0.515) \\
-0.129(0.131)\end{array}$ & $\begin{array}{r}1.017(0.315)^{* * *} \\
-0.13(0.058)^{*} \\
0.427(0.525) \\
-0.098(0.131)\end{array}$ \\
\hline
\end{tabular}

${ }^{* * *} \mathrm{P}<0.001,{ }^{* *} \mathrm{P}<0.01,{ }^{*} \mathrm{P}<0.05,+\mathrm{P}<0.1$ estimated standard errors are in parentheses

We propose that there is a negative relationship between entry platform NW and morality of a complementor in $\mathrm{H} 2$, but the result shows that $\mathrm{H} 2$ is not statistically significant. In the hypothesis, we assume that when complementors adopt generalist's platform NW by providing services to multiple platforms, they are able to expand the customer base quickly, thereby increasing the likelihood of service success and lowering the mortality rate. However, statistic results reveal that generalist strategy did not positively impact the survival of the complementors. This result can be explained in terms of organizational capability. If complementors provide games to multiple platforms, it is necessary to convert the games according to specific technology of each platform. This requires organizational capability that enables the development of a game in multiple versions and achievement of the same quality level for each platform. However, right after the founding of the organization, complementors do not have sufficient organizational competence to do so, thus the strategy of broadening platform NW does not have significant impact on the complementor's mortality rate.

In the case of $\mathrm{H} 3$, we predict that entry genre NW would positively affect the mortality of a complementor and we note a positive coefficient for the entry NW and mortality of a complementor (Model II: beta $=0.38, \mathrm{p}<.001$ ), supporting H3. Hence, focusing on specialized genres is beneficial for the organization survival.

In $\mathrm{H} 4$, we predict that there is an inverted $\mathrm{U}$ relationship between a platform NW and mortality of a complementor. According to Table 2 platform NW related positively to mortality of a complementor 
(Model III: beta=1.013, $\mathrm{p}<.001$ ), but the quadratic term exhibited a negative relationship (Model III: beta=$0.134, \mathrm{p}<.05)$. Therefore, a platform NW display a curvilinear relationship with mortality of a complementor, in support of H4. Lastly, we propose that there is an inverted-U relationship between genre NW and mortality of a complementor in H5. Statistically, H5 is not supported which may be due to the unique feature of the game industry. In the game industry, it seems that other factors such as the characters in the game greatly influence the development of identity. When the game is introduced for the first time to the users, there is no information regarding the complementor, so the users evaluate the organization based on the game genre. As the number of user increases, users tend to develop the identity of complementors based on the characters of the game, representing the game developer. Thus, the effect of genre on the development of identity becomes limited.

\section{Discussion}

In this study, we observe the two aspects of network effect. First aspect has positive impacts by facilitating the growth of the platform, while second aspect involves negative effect on the complementors by increasing their mortality rate. In the platform environment, the complementor uses different strategies in a timely manner. When entering to a platform, by focusing on specific genres with a specialist's narrow genre NW, the complementor allows quick recognition of the organizational identity by the users. On the other hand, when the platform is growing, complementors adapt one of either platform NW of a generalist or a specialist. Broadening platform NW expands customer base by providing services to multiple platforms while narrow platform NW offers the capability to provide optimized service to users in a specific platform.

Through the statistical analyses, we confirm that the strategic behaviors of the complementor impact the entire platform in several ways. First, the competition among complementors resulted from the platform growth increases the mortality rate of complementors, which acts as an obstacle for the platform owner to continually provide new services. Hence, the platform owner needs to adopt strategy such as complementor management strategy and strategic alliance that enables platform to continuously attract new complementors into the platform and retain them. Second, in the early stage of the platform, although implementing specialist's genre NW decreases the mortality rate, it also prevents platform owners to provide a variety of services to the users. As not being able to provide diversified services to the users, the ability of platform to attract new users and facilitate network effect is limited. Thus, the platform owner must prevent the situation of complementors' services being biased toward a specific genre at the early phase of the platform.

This study includes several limitations that need to be taken into account in interpreting the results. First, during the process of statistical analysis, we include the characteristic of platform as a dummy variable. Nonetheless, each platform possesses unique characteristic that represents the technological aspect of the platform and policy that influence the strategic decision of complementors. Second, this research examines the strategy of complementors in platforms during the entrance and growth. However, the platform itself also experiences the process of founding, expansion and obsolescence and these the platform lifecycle influences the strategic behaviors of the complementors. However, we did not incorporate lifecycle of platform.

In sum, we investigate the strategic behaviors of complementors and their impacts on the platform. This paper provides theory and interpretations on various strategic behaviors of complementor. By understanding complementors' strategic behaviors and their effects on the platform dynamics, we suggest that the platform owner needs to flexibly cope with the strategic changes of individual complementor.

\section{References}

[1] N. Economides, E. Katsamakas, Two-sided competition of proprietary vs. open source technology platforms and the implications for the software industry, Management Science, 52 (2006) 1057-1071.

[2] M.L. Katz, C. Shapiro, Technology adoption in the presence of network externalities, Journal of political economy, 94 (1986) 822-841.

[3] E.G. Anderson, G.G. Parker, B. Tan, Platform Performance Investment in the Presence of Network Externalities, Information Systems Research, 25 (2014) 152-172.

[4] D.S. Evans, A. Hagiu, R. Schmalensee, Invisible engines: how software platforms drive innovation and transform industries, MIT press, 2008.

[5] T.R. Eisenmann, G. Parker, M.W. Van Alstyne, Opening platforms: how, when and why?, (2008).

[6] A. Gawer, M.A. Cusumano, Platform leadership: How Intel, Microsoft, and Cisco drive industry innovation, Harvard Business School Press Boston, 2002.

[7] T. Eisenmann, G. Parker, M.W. Van Alstyne, Strategies for two-sided markets, Harvard business review, 84 (2006) 92.

[8] J. West, How open is open enough?: Melding proprietary and open source platform strategies, Research policy, 32 (2003) 1259-1285.

[9] A. Benlian, D. Hilkert, T. Hess, How open is this platform? The meaning and measurement of platform 
openness from the complementors' perspective, Journal of Information Technology, 30 (2015) 209-228.

[10] K. Boudreau, Open platform strategies and innovation: Granting access vs. devolving control, Management Science, 56 (2010) 1849-1872.

[11] M.L. Katz, C. Shapiro, Network externalities, competition, and compatibility, The American economic review, 75 (1985) 424-440.

[12] G.G. Parker, M.W. Van Alstyne, Two-sided network effects: A theory of information product design, Management science, 51 (2005) 1494-1504.

[13] K.J. Boudreau, L.B. Jeppesen, Unpaid crowd complementors: The platform network effect mirage, Strategic Management Journal, 36 (2015) 1761-1777.

[14] M. Sun, E. Tse, The Resource-Based View of Competitive Advantage in Two-Sided Markets, Journal of Management Studies, 46 (2009) 45-64.

[15] M. Sun, E. Tse, When does the winner take all in twosided markets?, Review of Network Economics, 6 (2007).

[16] J.C. Rochet, J. Tirole, Two-sided markets: a progress report, The RAND journal of economics, 37 (2006) 645-667.

[17] S. Athey, E. Calvano, J.S. Gans, The impact of consumer multi-homing on advertising markets and media competition, Management Science, (2016).

[18] V. Landsman, S. Stremersch, Multihoming in two-sided markets: An empirical inquiry in the video game console industry, Journal of Marketing, 75 (2011) 39-54.

[19] M.T. Hannan, J. Freeman, Organizational ecology, Harvard University Press, 1993.

[20] G.R. Carroll, M.T. Hannan, The demography of corporations and industries, Princeton University Press, 2000 [21] J. Freeman, M.T. Hannan, Niche width and the dynamics of organizational populations, American Journal of Sociology, 88 (1983) 1116-1145.

[22] M.T. Hannan, G.R. Carroll, S.D. Dobrev, J. Han, Organizational mortality in European and American automobile industries Part I: Revisiting the effects of age and size, European Sociological Review, 14 (1998) 279-302.

[23] M.T. Hannan, G.R. Carroll, S.D. Dobrev, J. Han, J.C. Torres, Organizational mortality in European and American automobile industries Part II: Coupled clocks, European Sociological Review, 14 (1998) 303-313.

[24] S.D. Dobrev, The dynamics of the Bulgarian newspaper industry in a period of transition: Organizational adaptation, structural inertia and political change, Industrial and corporate change, 8 (1999) 573-605.

[25] H.E. Kwon, W. Oh, T.-H. Kim, One-Sided Competition in Two-Sided Social Platform Markets? An Organizational Ecology Perspective, (2015).

[26] M. McPherson, An ecology of affiliation, American Sociological Review, (1983) 519-532.

[27] G.R. Carroll, M.T. Hannan, Density delay in the evolution of organizational populations: A model and five empirical tests, Administrative Science Quarterly, (1989) 411-430.

[28] M.T. Hannan, J. Freeman, The population ecology of organizations, American journal of sociology, (1977) 929964.
[29] J.A. Baum, S.J. Mezias, Localized competition and organizational failure in the Manhattan hotel industry, 18981990, Administrative Science Quarterly, (1992) 580-604.

[30] M.T. Hannan, G.R. Carroll, Dynamics of organizational populations: Density, legitimation, and competition, Oxford University Press, 1992.

[31] M.T. Hannan, Ecologies of organizations: Diversity and identity, Journal of Economic Perspectives, (2005) 51-70.

[32] M.T. Hannan, L. Pólos, G.R. Carroll, Logics of organization theory: Audiences, codes, and ecologies, Princeton University Press, 2007.

[33] M. Armstrong, J. Wright, Two-sided markets, competitive bottlenecks and exclusive contracts, Economic Theory, 32 (2007) 353-380.

[34] K.S. Corts, M. Lederman, Software exclusivity and the scope of indirect network effects in the US home video game market, international Journal of industrial Organization, 27 (2009) 121-136.

[35] R. Mantena, R. Sankaranarayanan, S. Viswanathan, Platform-based information goods: The economics of exclusivity, Decision Support Systems, 50 (2010) 79-92.

[36] S. Hyrynsalmi, A. Suominen, S. Jansen, K. Yrjönkoski, Multi-homing in ecosystems and firm performance: Does it improve software companies' ROA?, in: IWSECO@ ICIS, 2016, pp. 56-69.

[37] E.W. Zuckerman, The categorical imperative: Securities analysts and the illegitimacy discount, American journal of sociology, 104 (1999) 1398-1438.

[38] E.W. Zuckerman, T.Y. Kim, K. Ukanwa, J. Von Rittmann, Robust Identities or Nonentities? Typecasting in the Feature-Film Labor Market1, American Journal of Sociology, 108 (2003) 1018-1073.

[39] G. Hsu, M.T. Hannan, Identities, genres, and organizational forms, Organization Science, 16 (2005) 474490.

[40] T. Doganoglu, J. Wright, Multihoming and compatibility, International Journal of Industrial Organization, 24 (2006) 45-67.

[41] E.W. Zuckerman, T.-Y. Kim, K. Ukanwa, J. Von Rittmann, robust identities or nonentities? Typecasting in the feature-film labor market 1, American Journal of Sociology, 108 (2003) 1018-1074.

[42] J.D. Carrillo, Platform competition: The role of multihoming and complementors, (2006).

[43] A. Swaminathan, Resource partitioning and the evolution of specialist organizations: The role of location and identity in the US wine industry, Academy of Management Journal, 44 (2001) 1169-1185.

[44] H.A. Haveman, Follow the leader: Mimetic isomorphism and entry into new markets, Administrative science quarterly, (1993) 593-627.

[45] M.T. Hannan, J.N. Baron, G. Hsu, Ö. Koçak, Organizational identities and the hazard of change, Industrial and Corporate Change, 15 (2006) 755-784.

[46] J. Chu, P. Manchanda, Quantifying cross and direct network effects in online C2C platforms, Marketing Science, Forthcoming, (2015). 